Check for updates

Cite this: RSC Adv., 2018, 8, 37243

Received 11th October 2018

Accepted 30th October 2018

DOI: $10.1039 / \mathrm{c} 8 \mathrm{ra0} 8429 \mathrm{~g}$

rsc.li/rsc-advances

\section{At room temperature in water: efficient hydrogenation of furfural to furfuryl alcohol with a $\mathrm{Pt} / \mathrm{SiC}-\mathrm{C}$ catalyst}

\author{
Guimei Wang, Ruihua Yao, Huiyue Xin, Yejun Guan, (D) Peng Wu (iD \\ and Xiaohong Li iD *
}

\begin{abstract}
Selective hydrogenation of furfural (FAL) to furfuryl alcohol (FOL) is challenging because of many side reactions. The highly selective hydrogenation of $\mathrm{FAL}$ to $\mathrm{FOL}$ can be achieved over a Pt catalyst supported on nanoporous $\mathrm{SiC}-\mathrm{C}$ composites even at room temperature in water. A Pt/SiC $-\mathrm{C}-200-\mathrm{H}_{2}$ catalyst, which had a Pt loading of $3 \mathrm{wt} \%$ and was reduced in flowing hydrogen at $500{ }^{\circ} \mathrm{C}$ after calcination in air at $200{ }^{\circ} \mathrm{C}$ for $2 \mathrm{~h}$, furnished complete $\mathrm{FAL}$ conversion and over $99 \%$ selectivity to $\mathrm{FOL}$ at $25{ }^{\circ} \mathrm{C}$ under $1 \mathrm{MPa}$ of hydrogen in water. The kinetic behaviour of the selective hydrogenation of FAL to FOL with the $3 \mathrm{wt} \% \mathrm{Pt} / \mathrm{SiC}-\mathrm{C}-200-\mathrm{H}_{2}$ catalyst was also investigated and the turnover frequency (TOF) reached 1148 $\mathrm{h}^{-1}$. Moreover, the $\mathrm{Pt} / \mathrm{SiC}-\mathrm{C}$ catalyst is more active than other $\mathrm{Pt}$ catalysts supported on ordered mesoporous carbon CMK-3, activated carbon, periodic mesoporous silica SBA-15 or $\mathrm{Al}_{2} \mathrm{O}_{3}$. Detailed characterization using XRD, N2-sorption, SEM, TEM and XPS techniques reveals that the striking performance of the $\mathrm{Pt} / \mathrm{SiC}-\mathrm{C}$ catalyst can be attributed to the optimal metal-support interaction and the interfacial effect.
\end{abstract}

\section{Introduction}

Over the last few decades, the conversion of biomass-derived molecules to fuels or chemicals has attracted much attention because of the major concerns related to global warming from anthropogenic emissions of green-house gases, climate change, and depletion of fossil fuels. ${ }^{1-4}$ Furfural (FAL), derived from hemicellulose, is a key platform compound which can be widely converted to a variety of chemicals and biofuels. ${ }^{5,6}$ Hydrogenation is one of the potential routes for FAL conversion. However, due to complicated reaction networks, many products including furfuryl alcohol (FOL), tetrahydrofuran (THF) and tetrahydrofurfuryl alcohol (THFOL) can be achieved via hydrogenation of FAL (Scheme 1). ${ }^{6}$ FOL is an important chemical intermediate because it has been widely applied in the synthesis of fine chemicals and polymers. For instance, FOL has been intensively utilized for the production of thermostatic resins, acid-proof bricks, corrosion-resistant fiber glass, lysine, vitamin $\mathrm{C}$ and lubricants. ${ }^{7,8}$ According to the statistics, $62 \%$ of global FAL was converted to FOL. ${ }^{9}$

However, during the hydrogenation of FAL, dehydrogenation or decarbonylation can simultaneously take place, thus the selective formation of FOL is very challenging and highly

Shanghai Key Laboratory of Green Chemistry and Chemical Processes, School of Chemistry and Molecular Engineering, East China Normal University, 3663 North Zhongshan Rd., Shanghai 200062, China. E-mail: xhli@chem.ecnu.edu.cn; Fax: +8621-62238590; Tel: +86-21-62238590 selective catalysts are needed. It is well known that copper chromite (Cu-Cr) catalysts are the most successful commercial catalysts in FAL hydrogenation processes for over five decades. Up to $98 \%$ of selectivity to FOL in either liquid or gas phase can be achieved on the $\mathrm{Cu}-\mathrm{Cr}$ catalysts in various industrial processes. ${ }^{1}$ Nonetheless, stringent reaction conditions such as high temperature (up to $180{ }^{\circ} \mathrm{C}$ ) and high hydrogen pressure (70-100 bar) are required in order to obtain medium FAL conversion and high selectivity to FOL. ${ }^{10}$ Moreover, the catalytic process using $\mathrm{Cu}-\mathrm{Cr}$ catalysts suffer from a drawback of high toxicity that causes severe environmental pollution after catalyst final disposal. To overcome this, chromium-free catalysts and noble metal promoted Cu-based catalysts have been developed. ${ }^{11-18}$ For instance, Fulajtarova et al. prepared a $\mathrm{Pd}-\mathrm{Cu} / \mathrm{MgO}$ catalyst for hydrogenation of FAL and a high FOL selectivity of 99\% was obtained at $40{ }^{\circ} \mathrm{C} .{ }^{13} \mathrm{~A} \mathrm{Cu} / \mathrm{MgO}$ catalyst also behaved well in the hydroconversion of FAL to FOL in vapor phase under the optimal conditions. ${ }^{\mathbf{1 4 , 1 5}}$ Besides, noble-metal catalysts also aroused intensive interests in this field. ${ }^{19-21}$

Among the various noble metal catalysts, Pt-based catalysts have been widely applied in various hydrogenation reactions due to their unique properties. ${ }^{22-25}$ Particularly, Pt-based catalysts were also employed in the selective hydrogenation of FAL to FOL. ${ }^{26-29,31}$ For example, Vaidya et al. used a Pt/C catalyst for FAL hydrogenation in a slurry reactor although the reaction rate was slow and the FOL selectivity was $96 \% .^{26}$ Kyriakou et al. also prepared various Pt catalysts supported on $\mathrm{SiO}_{2}, \mathrm{ZnO}, \gamma-\mathrm{Al}_{2} \mathrm{O}_{3}, \mathrm{CeO}_{2}$ and $\mathrm{MgO}$ and they found that the Pt/ 


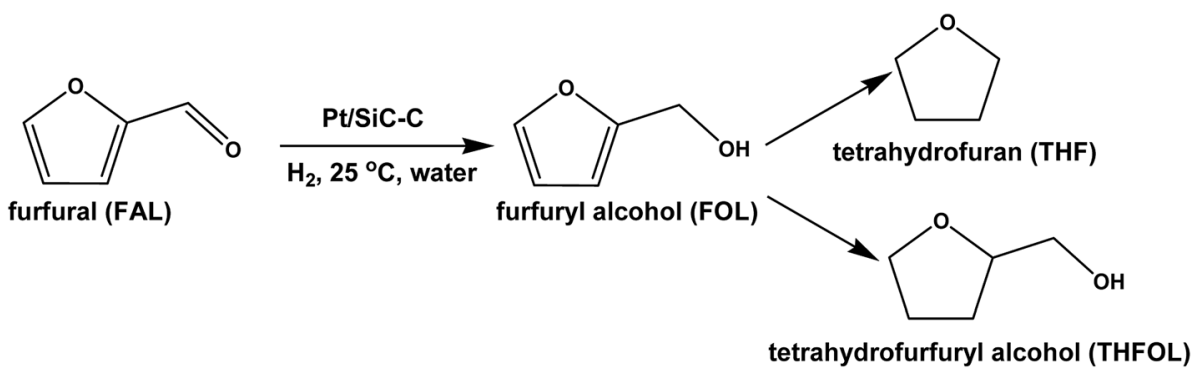

Scheme 1 Liquid-phase selective hydrogenation of furfural (FAL) to furfuryl alcohol (FOL) with a Pt catalyst supported on SiC-C composites at room temperature in neat water

$\gamma-\mathrm{Al}_{2} \mathrm{O}_{3}$ catalyst showed relatively good performance at $50{ }^{\circ} \mathrm{C}$ (an FAL conversion of $80 \%$ and an FOL selectivity of $99 \%$ after $7 \mathrm{~h}$ reaction), with atmospheric hydrogen and methanol as solvent. However, the substrate/catalyst ratio is very limited. ${ }^{27}$ Recently, Srinivas et al. prepared a $\mathrm{Pt} / \gamma-\mathrm{Al}_{2} \mathrm{O}_{3}$ catalyst for the selective hydrogenation of FAL and an FOL selectivity of $98.1 \%$ was obtained. ${ }^{28}$ Nevertheless, the reaction conditions were not mild and the activity was low.

As mentioned above, it is still a great challenge to design environmentally friendly, active and selective catalysts for the liquid-phase FAL hydrogenation to FOL under mild conditions such as at room temperature under relatively lower hydrogen pressure. Herein, we report our efforts in the selective hydrogenation of FAL to FOL in a greener manner, which is, conducting the selective hydrogenation of FAL in water at room temperature with a Pt catalyst supported on nanoporous $\mathrm{SiC}-\mathrm{C}$ composites. Silicon carbide $\mathrm{SiC}$, as one of the most important semiconductors, has attracted much more attention in optical and electrical fields recently, due to its wide bandgap, high strength, high thermal conductivity, good thermal shock resistance, low thermal expansion and good chemical inertness. ${ }^{32}$ However, SiC alone has a relatively low specific surface area (usually below $100 \mathrm{~m}^{2} \mathrm{~g}^{-1}$ ). Therefore, nanoporous SiC-C composites were synthesized in order to obtain high surface area and combine the properties of activated carbon and SiC. More importantly, the Pt/ SiC-C catalysts were proved highly active and selective for the liquid-phase hydrogenation of cinnamaldehyde under the milder conditions. ${ }^{33}$ When subjected to the selective hydrogenation of FAL, the Pt/SiC-C catalyst also afforded FOL with extremely high selectivity. Under the tested reaction conditions such as in water at $25{ }^{\circ} \mathrm{C}$ under $1 \mathrm{MPa}$ of hydrogen pressure, both the FAL conversion and the FOL selectivity can reach over $99 \%$.

\section{Experimental section}

\subsection{Chemicals}

$\mathrm{H}_{2} \mathrm{PtCl}_{6} \cdot 6 \mathrm{H}_{2} \mathrm{O}$ (Pt $\left.\geq 37 \%\right)$, FAL and other reagents were purchased from Sinopharm Group Co. Ltd and used as received. FOL, $5 \mathrm{wt} \% \mathrm{Pt} / \mathrm{Al}_{2} \mathrm{O}_{3}$ and $5 \mathrm{wt} \% \mathrm{Pt} / \mathrm{C}$ catalysts were purchased from Alfa Aesar. SiC-C composites were provided by Suzhou Yuhao Nanomaterial Inc. (Suzhou, China) and used as received.

\subsection{Catalyst preparation}

The $\mathrm{Pt} / \mathrm{SiC}-\mathrm{C}-\mathrm{H}_{2}$ catalyst was prepared using an ultrasoundpromoted impregnation method which was described elsewhere. ${ }^{33}$ In this case, the catalyst precursor was reduced in flowing hydrogen $\left(99.999 \%, 40 \mathrm{ml} \mathrm{min}^{-1}\right)$ at $500{ }^{\circ} \mathrm{C}$ for $3 \mathrm{~h}$. The resulting catalyst was designated as $x \mathrm{wt} \% \mathrm{Pt} / \mathrm{SiC}-\mathrm{C}-\mathrm{H}_{2}$, where $x$ refers to the Pt weight percentage in the catalyst. In some cases, the catalyst precursor was calcined in static air at $200^{\circ} \mathrm{C}$ for $2 \mathrm{~h}$ before the reduction treatment and the resulting catalyst was denoted as $x$ wt $\% \mathrm{Pt} / \mathrm{SiC}-\mathrm{C}-200-\mathrm{H}_{2}$. For comparison, $x$ wt $\% \mathrm{Pt} /$ SiC-C-SF catalyst was prepared in a similar manner as that for the $x \mathrm{wt} \% \mathrm{Pt} / \mathrm{SiC}-\mathrm{C}-\mathrm{H}_{2}$ catalyst, except that the catalyst was reduced by sodium formate in water at $95^{\circ} \mathrm{C}$. In addition, $5 \mathrm{wt} \%$ $\mathrm{Pt} / \mathrm{SBA}-15,5 \mathrm{wt} \% \mathrm{Pt} / \mathrm{CMK}-3$ were also prepared using the same method. The $5 \mathrm{wt} \% \mathrm{Pt} / \mathrm{C}$ and $\mathrm{Pt} / \mathrm{Al}_{2} \mathrm{O}_{3}$ catalysts bought from Alfa Aesar were also used for comparison.

\subsection{Catalyst characterization}

The structure and crystalline phase of the samples was characterized with a Bruker D8 Advance X-ray diffractometer (XRD) using $\mathrm{Cu}-\mathrm{K} \alpha$ radiation. The specific surface area and pore volume of the samples were calculated using the adsorption branch from the nitrogen sorption isotherms at liquid nitrogen temperature $(77 \mathrm{~K})$ on a Quantachrome Autosorb-3B system, after the samples were outgassed at $200{ }^{\circ} \mathrm{C}$ for $10 \mathrm{~h}$. The morphology of the samples were characterized with a Hitachi S4800 scanning electron microscope (SEM) operated at $20 \mathrm{kV}$. The Pt particle size and distribution was characterized with an FEI Tecnai G2-TF30 transmission electron microscope operated at $300 \mathrm{kV}$. X-ray photoelectronic spectroscopy (XPS) measurements were performed on a Thermo Fisher Scientific ESCALAB 250Xi spectrometer with Al $\mathrm{K} \alpha$ radiation $(1486.6 \mathrm{eV}$ ) as an incident beam with a monochromator. Before the measurement, the sample was in situ pre-treated in flowing hydrogen at $400{ }^{\circ} \mathrm{C}$ for $2 \mathrm{~h}$ in a reactor attached to the XPS spectrometer. The binding energy (BE) was calibrated using $\mathrm{C}-\mathrm{C}$ binding energy at $284.9 \mathrm{eV}$. The spectra have been calibrated by subtraction of a Shirley background. The XPSPEAK software was applied for spectral fitting and peak integration.

\subsection{Catalytic evaluation}

For a standard reaction, $20 \mathrm{mg}$ of the catalyst was firstly pretreated in flowing hydrogen $\left(99.999 \%, 40 \mathrm{ml} \mathrm{min}^{-1}\right)$ at $400{ }^{\circ} \mathrm{C}$ 
for $2 \mathrm{~h}$. The catalyst was then transferred to an autoclave (100 $\mathrm{ml}$ ) after mixing with $10 \mathrm{ml}$ of water to avoid contact with air. Then, $300 \mu \mathrm{l}$ of FAL was added to the autoclave. The hydrogenation started with electronically stirred at $1200 \mathrm{rpm}$ after hydrogen (1.0 MPa) was introduced. The temperature was controlled at $25{ }^{\circ} \mathrm{C}$. The reaction was terminated after $3-5 \mathrm{~h}$ and the products were analyzed using GC-FID (GC-2014, Shimadzu) equipped with a capillary column (DM-WAX, $30 \mathrm{~m} \times 0.25 \mathrm{~mm}$ $\times 0.25 \mu \mathrm{m})$. For recycling experiments, the catalyst was recovered by centrifugation and washed with water for three times after each run. Then, water and FAL were re-charged to the autoclave together with the recovered catalyst to perform the next run reaction.

\section{Results and discussion}

\subsection{Characterizations of the $\mathrm{Pt} / \mathrm{SiC}-\mathrm{C}$ catalysts}

The structures of the SiC-C composites and the Pt/SiC-C catalysts were characterized using XRD. As shown in Fig. 1, the SiC$\mathrm{C}$ composites give typical diffraction patterns associated to (111), (220) and (311) planes of $\beta$-SiC, along with weak stacking faults at the 2 theta of $35^{\circ} .^{32}$ In addition, the diffraction peak assigned to amorphous carbon is also observed at around 2 theta of $25^{\circ}$, verifying that besides $\beta$-SiC, there is also amorphous carbon. The $\beta$-SiC crystalline phase is well retained in the final $\mathrm{Pt} / \mathrm{SiC}-\mathrm{C}$ catalysts, which is confirmed by the patterns of the $\mathrm{Pt} / \mathrm{SiC}-\mathrm{C}$ catalysts. Moreover, the $\mathrm{Pt} / \mathrm{SiC}-\mathrm{C}$ catalysts also give typical but weak diffractions assigned to $\operatorname{Pt}(111), \operatorname{Pt}(200)$ and $\mathrm{Pt}(220)$ planes, indicating that the Pt particles are well dispersed on the SiC-C surface without the formation of large aggregations.

The porous structure and specific surface area of the typical $\mathrm{Pt} / \mathrm{SiC}-\mathrm{C}$ catalysts was determined by nitrogen sorption. The BET specific surface area of $\mathrm{Pt} / \mathrm{SiC}-\mathrm{C}$ is comparable with that of the SiC-C composites, with a surface area of about $330-340 \mathrm{~m}^{2}$ $\mathrm{g}^{-1}$. The pore volume of the $\mathrm{Pt} / \mathrm{SiC}-\mathrm{C}$ catalyst retains $0.5 \mathrm{~cm}^{3}$

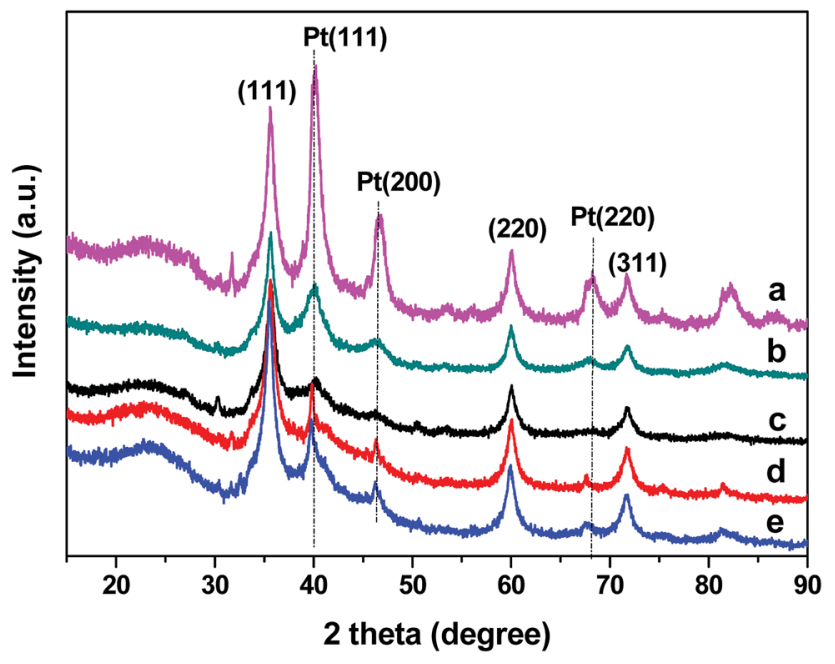

Fig. 1 XRD patterns of (a) $5 \mathrm{wt} \% \mathrm{Pt} / \mathrm{SiC}-\mathrm{C}-\mathrm{H}_{2}$, (b) $5 \mathrm{wt} \% \mathrm{Pt} / \mathrm{SiC}-\mathrm{C}-\mathrm{SF}$, (c) $3 \mathrm{wt} \% \mathrm{Pt} / \mathrm{SiC}-\mathrm{C}-\mathrm{SF}$, (d) $3 \mathrm{wt} \% \mathrm{Pt} / \mathrm{SiC}-\mathrm{C}-\mathrm{H}_{2}$, and (e) $3 \mathrm{wt} \% \mathrm{Pt} / \mathrm{SiC}-$ C- $200-\mathrm{H}_{2}$ $\mathrm{g}^{-1}$, demonstrating that the deposition of Pt nanoparticles does not block the pore entrance of the SiC-C composites. The pore size of $\mathrm{Pt} / \mathrm{SiC}-\mathrm{C}$ and $\mathrm{SiC}-\mathrm{C}$ centres at $3.6 \mathrm{~nm}$. The detailed physico-chemical parameters of the relevant catalysts are listed in Table 1 for clarity.

The morphology of the $\mathrm{SiC}-\mathrm{C}$ composites was characterized using SEM (Fig. 2). The SiC-C composites exhibited irregular shapes with broccoli-like aggregations. The Pt particle size distribution of the typical $\mathrm{Pt} / \mathrm{SiC}-\mathrm{C}$ catalyst was characterized using TEM (Fig. 3). For the $3 \mathrm{wt} \% \mathrm{Pt} / \mathrm{SiC}-\mathrm{C}-200-\mathrm{H}_{2}$ catalyst, the Pt nanoparticles are uniformly dispersed on the SiC-C surface with an average Pt particle size of $1.8 \mathrm{~nm}$ and $63 \%$ dispersion (Fig. 3a).

\subsection{Selective hydrogenation of FAL to FOL over the Pt/SiC-C catalysts}

In our previous studies, a $5 \mathrm{wt} \% \mathrm{Pt} / \mathrm{SiC}-\mathrm{C}-\mathrm{SF}$ catalyst, which had a Pt loading of $5 \mathrm{wt} \%$ and was reduced in an aqueous solution of sodium formate, was proved active and selective for the liquid-phase hydrogenation of cinnamaldehyde at room temperature. ${ }^{33}$ Thus, we firstly submitted the $5 \mathrm{wt} \% \mathrm{Pt} / \mathrm{SiC}-\mathrm{C}-$ SF catalyst to the liquid-phase hydrogenation of FAL in water at room temperature. As listed in Table 2, the $5 \mathrm{wt} \% \mathrm{Pt} / \mathrm{SiC}-\mathrm{C}-\mathrm{SF}$ catalyst gives $99.4 \%$ FAL conversion with $91.7 \%$ FOL selectivity within $5 \mathrm{~h}$. Although the FAL conversion is excellent, the FOL selectivity still needs to be improved. Then, we reduced the $5 \mathrm{wt} \% \mathrm{Pt} / \mathrm{SiC}-\mathrm{C}$ catalyst precursor in flowing hydrogen at $500{ }^{\circ} \mathrm{C}$. Unfortunately, the resultant $5 \mathrm{wt} \% \mathrm{Pt} / \mathrm{SiC}-\mathrm{C}-\mathrm{H}_{2}$ catalyst shows an FAL conversion of about $80 \%$ with an FOL selectivity of about $99 \%$ under the same reaction conditions. This indicates that the reduction method for the catalyst precursor will affect the catalytic performance obviously.

Meanwhile, owing to the high cost of noble-metal Pt catalyst, the $\mathrm{Pt} / \mathrm{SiC}-\mathrm{C}$ catalyst with lower Pt loading such as $3 \mathrm{wt} \%$ was also prepared using the same method and then applied for the selective hydrogenation of FAL. Similarly, the $3 \mathrm{wt} \% \mathrm{Pt} / \mathrm{SiC}-\mathrm{C}$ catalyst was also reduced using two methods just like the $5 \mathrm{wt} \%$ $\mathrm{Pt} / \mathrm{SiC}-\mathrm{C}$ catalysts. As a result, the similar phenomenon is also observed on the $3 \mathrm{wt} \% \mathrm{Pt} / \mathrm{SiC}-\mathrm{C}$ catalysts. The $3 \mathrm{wt} \% \mathrm{Pt} / \mathrm{SiC}-\mathrm{C}-$ $\mathrm{H}_{2}$ catalyst shows relatively lower FAL conversion but higher FOL selectivity than the $3 \mathrm{wt} \% \mathrm{Pt} / \mathrm{SiC}-\mathrm{C}-\mathrm{SF}$ catalyst. When the $\mathrm{Pt} / \mathrm{SiC}-\mathrm{C}$ catalysts were characterized by XRD (Fig. 1), it is found that the $\mathrm{Pt} / \mathrm{SiC}-\mathrm{C}-\mathrm{H}_{2}$ catalysts have relatively stronger $\mathrm{Pt}(111)$ diffractions than the ones reduced in an aqueous solution of sodium formate, indicating that Pt nanoparticles would aggregate to form relatively larger particles when reduced at an elevated temperature.

Considering that the $\mathrm{Pt} / \mathrm{SiC}-\mathrm{C}-\mathrm{H}_{2}$ catalyst has a comparatively lower activity but higher FOL selectivity, the catalytic activity of the $\mathrm{Pt} / \mathrm{SiC}-\mathrm{C}-\mathrm{H}_{2}$ catalyst is required to further improve. Calcining the catalyst precursor in static air at $200{ }^{\circ} \mathrm{C}$ before reduction in flowing hydrogen indeed improves its catalytic ability remarkably. Consequently, the $3 \mathrm{wt} \% \mathrm{Pt} / \mathrm{SiC}-\mathrm{C}-$ 200- $\mathrm{H}_{2}$ catalyst furnishes almost complete FAL conversion with the excellent $99.4 \%$ FOL selectivity. On recalling the XRD patterns of Pt catalysts (Fig. 1), the larger Pt nanoparticles tend 
Table 1 Physicochemical parameters for the $\mathrm{SiC}-\mathrm{C}$ and relevant Pt catalysts

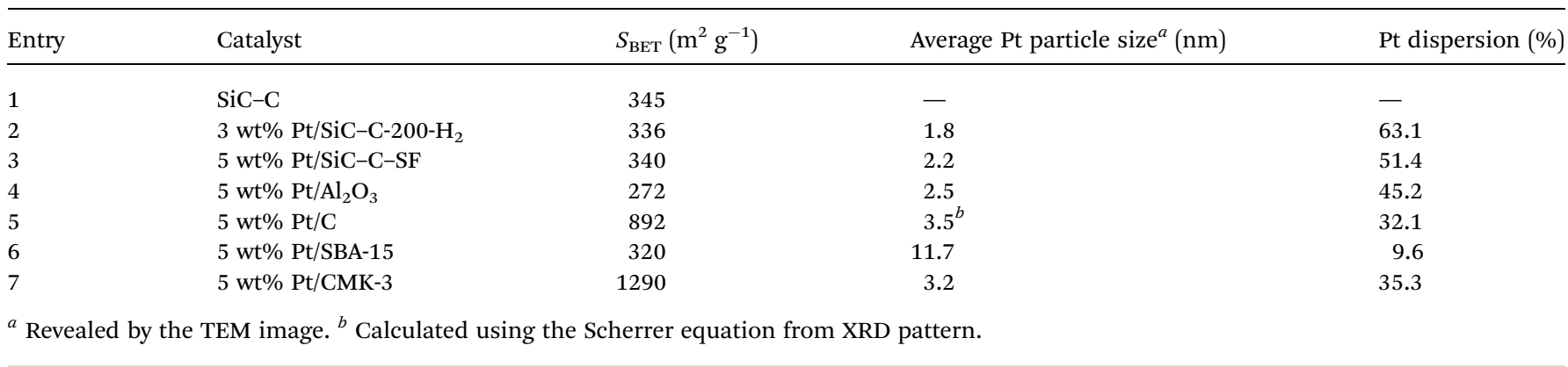

to give lower activity but higher selectivity to FOL. The $3 \mathrm{wt} \% \mathrm{Pt} /$ SiC-C-200- $\mathrm{H}_{2}$ catalyst also shows similar Pt(111) diffraction as the $3 \mathrm{wt} \% \mathrm{Pt} / \mathrm{SiC}-\mathrm{C}-\mathrm{H}_{2}$ catalyst, suggesting that the Pt nanoparticle diffraction or Pt nanoparticle size hardly changes after calcination in air before reduction using the same method. However, calcination of the catalyst precursor in air might modulate the surface electronic property, so that the $3 \mathrm{wt} \% \mathrm{Pt} /$ SiC-C-200- $\mathrm{H}_{2}$ catalyst can afford superior results. Another possible reason may be that calcination of the catalyst precursor in static air at $200{ }^{\circ} \mathrm{C}$ probably removes some residues on the SiC-C composite surface, because the SiC-C composite is used as received and there contains a large amount of carbon. ${ }^{33}$ Therefore, the $3 \mathrm{wt} \% \mathrm{Pt} / \mathrm{SiC}-\mathrm{C}-200-\mathrm{H}_{2}$ catalyst is selected as the standard catalyst in the subsequent studies.

Besides the catalyst preparation, reaction parameters such as solvent would also influence the catalytic performance. There are many solvents used for the tested reaction in literature, including polar solvents (isopropyl alcohol, ${ }^{28-30,34}$ methanol or ethanol $^{27}$ ) and non-polar solvents (octane, ${ }^{29}$ toluene ${ }^{27,29}$ ). In this study, we also compared the catalytic performance with the $3 \mathrm{wt} \% \mathrm{Pt} / \mathrm{SiC}-\mathrm{C}-200-\mathrm{H}_{2}$ catalyst for the selective hydrogenation of FAL in different solvents within $3 \mathrm{~h}$. As listed in Table 3, when the selective hydrogenation of FAL is conducted in a non-polar solvent such as octane, only $27.2 \%$ conversion is obtained with mediocre selectivity to FOL. When a polar solvent such as isopropanol is used as solvent, about $70 \% \mathrm{FAL}$ conversion is afforded with over $90 \%$ selectivity to FOL. As already mentioned above, the selective hydrogenation of FAL in water within $3 \mathrm{~h}$ furnishes about $80 \%$ FAL conversion with nearly $99 \%$ selectivity to FOL. It seems that the FAL hydrogenation performance increases as a sequence of in octane < in isopropyl alcohol $<$ in water. It agrees well with that the higher polarity of the solvent, the higher performance is obtained. The similar observation that the highest performance for the selective hydrogenation of FAL was achieved in water was also found in the literature. ${ }^{29,35}$

This can be interpreted by the solubility of FAL and FOL and by the soaking property of the $\mathrm{Pt} / \mathrm{SiC}-\mathrm{C}$ catalyst in different media. As clearly shown in the photographs in Fig. 4, FAL is slightly soluble in water and there is an opaque interface between water layer and FAL layer. When the Pt/SiC-C catalyst is submitted to the mixture of FAL/water, it is soaked well with the FAL layer. After overnight sedimentation, a clear interface between the water layer and the FAL layer is observed. With regards of FOL, it is relatively more soluble in water and the $\mathrm{Pt} /$ SiC-C catalyst is also soaked well with the aqueous solution of FOL. Even after overnight sedimentation, no obvious stratification is observed. Therefore, when the hydrogenation of FAL with the $\mathrm{Pt} / \mathrm{SiC}-\mathrm{C}$ catalyst is conducted in water, there would have an equilibrium move effect because once FOL is formed, it will be soluble in water and desorb from the catalyst surface, while the reactant FAL has an enriched concentration on the catalyst surface, resulting in an accelerated reaction. However, when the reaction is performed in octane, both FAL and FOL are insoluble in octane, so that the hydrogenation rate cannot be enhanced. The observations in this study are in good agreement with the literature. ${ }^{29,36}$

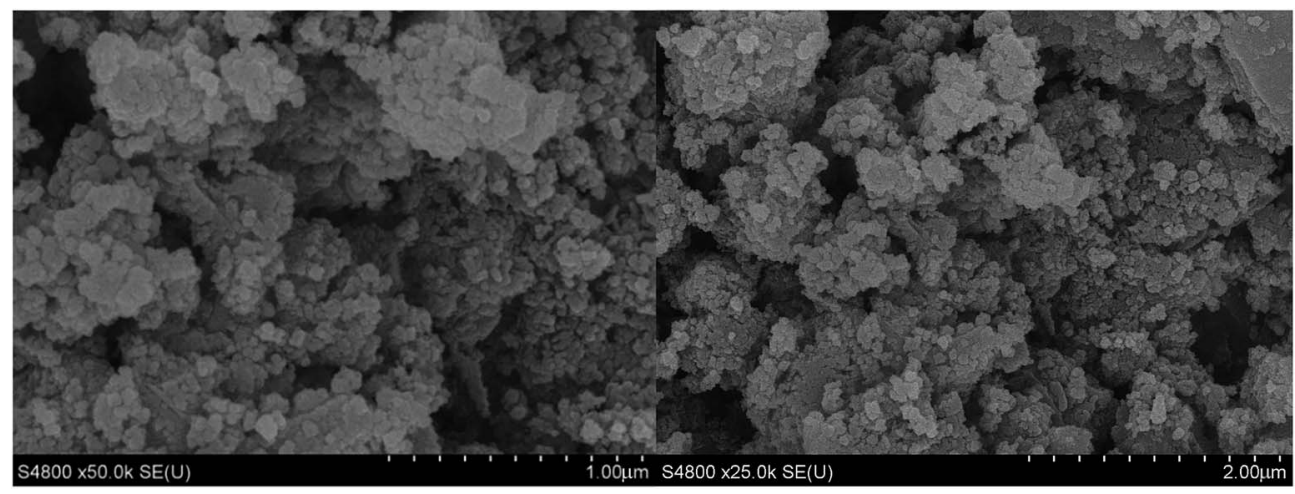

Fig. 2 SEM images of $\mathrm{SiC}-\mathrm{C}$ composites. 

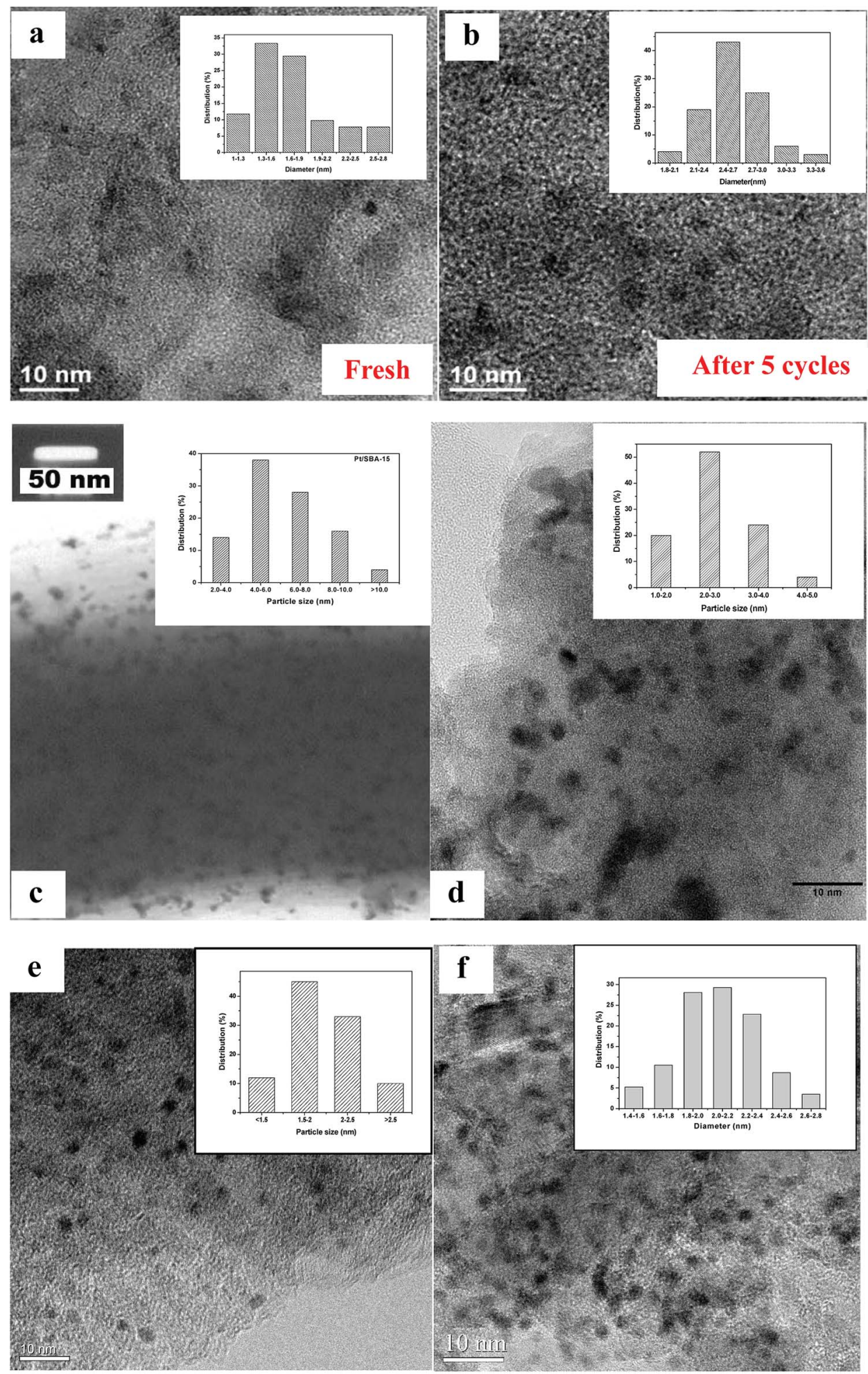

Fig. 3 TEM images of (a) the fresh and (b) used 3 wt\% Pt/SiC-C-200- $\mathrm{H}_{2}$ catalyst; (c) 5 wt\% Pt/SBA-15; (d) 5 wt\% Pt/Al $2 \mathrm{O}_{3}$; (e) 5 wt\% Pt/CMK-3 and (f) $5 \mathrm{wt} \% \mathrm{Pt} / \mathrm{C}$.

The kinetic behaviour of the selective hydrogenation of FAL was also studied with the $3 \mathrm{wt} \% \mathrm{Pt} / \mathrm{SiC}-\mathrm{C}-200-\mathrm{H}_{2}$ catalyst. As clearly displayed in Fig. 5, as the reaction progresses at room temperature in water, the FAL conversion increases quickly with reaction time. Consequently, more than $30 \%$ FAL conversion is obtained after $0.5 \mathrm{~h}$. Accordingly, the TOF (in terms of the number of moles of converted FAL per mole of Pt active sites per hour) reaches $1148 \mathrm{~h}^{-1}$. About $63 \%$ and 80\% FAL conversions 
Table 2 Results for the selective hydrogenation of FAL with different Pt catalysts ${ }^{a}$

\begin{tabular}{llllll}
\hline & & & \multicolumn{3}{l}{ Sel. (\%) } \\
\cline { 4 - 5 } Entry & Catalyst & Conv. (\%) & FOL & Others \\
\hline 1 & $5 \mathrm{wt} \% \mathrm{Pt} / \mathrm{SiC}-\mathrm{C}-\mathrm{SF}$ & 99.4 & 91.7 & 8.3 \\
2 & $5 \mathrm{wt} \% \mathrm{Pt} / \mathrm{SiC}-\mathrm{C}-\mathrm{H}_{2}$ & 79.9 & 99.2 & 0.8 \\
3 & $3 \mathrm{wt} \% \mathrm{Pt} / \mathrm{SiC}-\mathrm{C}-\mathrm{SF}$ & 99.5 & 97.8 & 2.2 \\
4 & $3 \mathrm{wt} \% \mathrm{Pt} / \mathrm{SiC}-\mathrm{C}-\mathrm{H}_{2}$ & 73.7 & 99.7 & 0.3 \\
5 & $3 \mathrm{wt} \% \mathrm{Pt} / \mathrm{SiC}-\mathrm{C}-200-\mathrm{H}_{2}$ & 99.5 & 99.4 & 0.6
\end{tabular}

${ }^{a}$ Reaction conditions: $20 \mathrm{mg}$ catalyst, $0.3 \mathrm{ml} \mathrm{FAL}, 10 \mathrm{ml}$ water, $25{ }^{\circ} \mathrm{C}$, 1.0 $\mathrm{MPa} \mathrm{H}_{2}, 1200 \mathrm{rpm}, 5 \mathrm{~h}$. Others: THF and THFOL.

Table 3 Selective hydrogenation of FAL with the 3 wt\% Pt/SiC-C$200-\mathrm{H}_{2}$ catalyst in different solvents ${ }^{a}$

\begin{tabular}{lllll}
\hline & & & \multicolumn{2}{l}{ Sel. (\%) } \\
\cline { 4 - 5 } Entry & Solvent & Conv. (\%) & FOL & Others \\
\hline 1 & Octane & 27.2 & 68.4 & 31.6 \\
2 & Isopropanol & 67.8 & 92.3 & 7.7 \\
3 & Water & 80.2 & 98.4 & 1.6
\end{tabular}

${ }^{a}$ Reaction conditions: $20 \mathrm{mg}$ catalyst, $0.3 \mathrm{ml} \mathrm{FAL}, 10 \mathrm{ml}$ water, $25{ }^{\circ} \mathrm{C}$, 1.0 $\mathrm{MPa} \mathrm{H}_{2}, 1200 \mathrm{rpm}, 3$ h. Others: THF and THFOL. are achieved within $1.5 \mathrm{~h}$ and $3 \mathrm{~h}$, respectively. Finally, FAL is almost fully converted within $4 \mathrm{~h}$. As for the FOL selectivity, it remains almost constant $(>97 \%)$ during the whole process. This indicates that the hydrogenation of FAL under the tested conditions is not a sequential reaction and without further hydrogenation or hydrolysis.

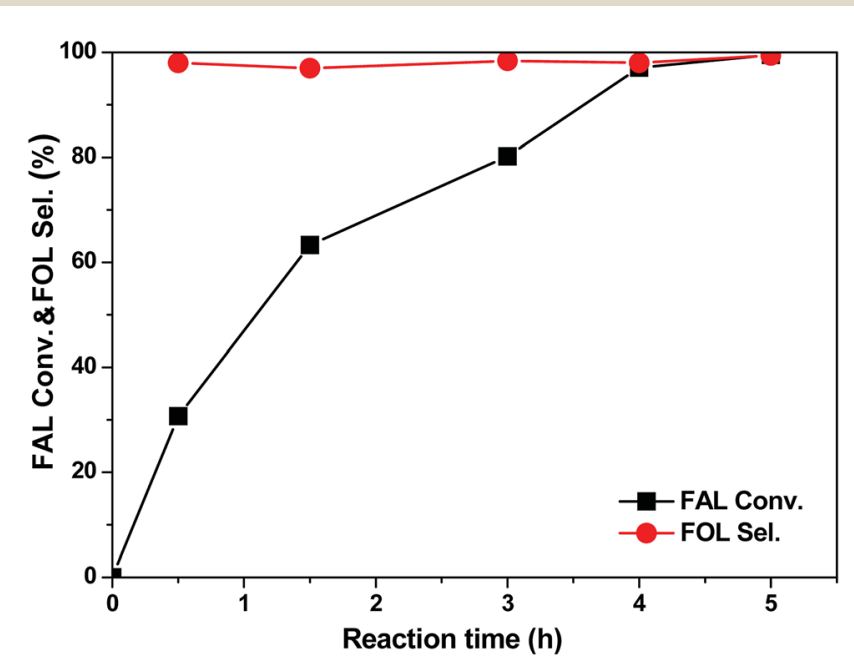

Fig. 5 Kinetic profile of the selective hydrogenation of FAL with the $3 \mathrm{wt} \% \mathrm{Pt} / \mathrm{SiC}-\mathrm{C}-200-\mathrm{H}_{2}$ catalyst. Reaction conditions: $20 \mathrm{mg}$ catalyst, $0.3 \mathrm{ml} \mathrm{FAL}, 10 \mathrm{ml}$ water, $25^{\circ} \mathrm{C}, 1.0 \mathrm{MPa} \mathrm{H}, 1200 \mathrm{rpm}$.
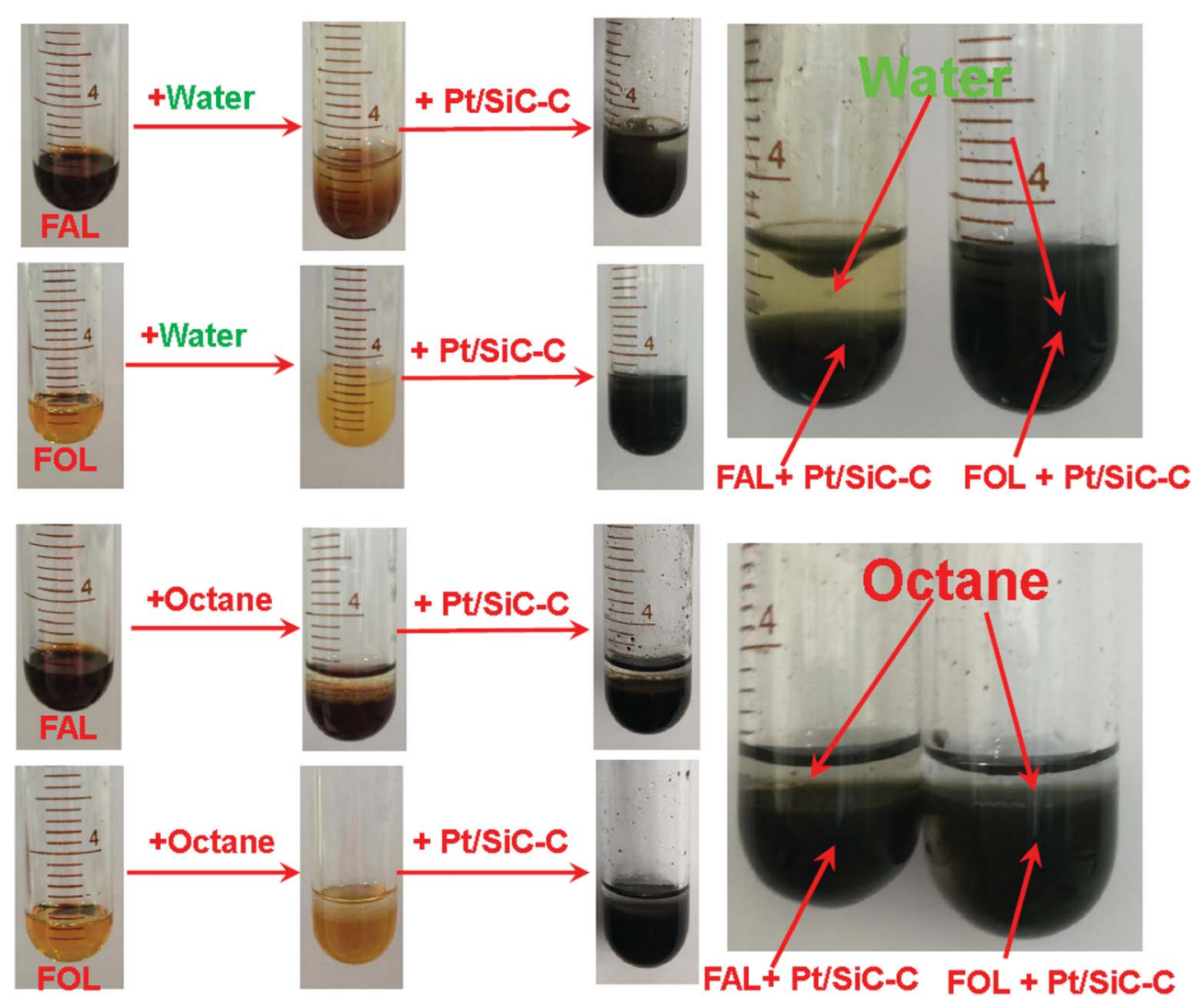

Fig. 4 The soakage property of the $\mathrm{Pt} / \mathrm{SiC}-\mathrm{C}$ catalyst in different media. 
Besides, the effect of FAL concentration on the catalytic performance was also addressed. We change the FAL concentration in two ways, one way is using different solvent volumes with the constant FAL amount and the other is addition of different FAL amount in a designated solvent volume. Table 4 gives the detailed results. Under the standard conditions, $300 \mu \mathrm{l}$ of FAL in $10 \mathrm{ml}$ of water gave $80.2 \%$ conversion within $3 \mathrm{~h}$. If the solvent volume was increased to $15 \mathrm{ml}$, lower FAL conversion of $67.7 \%$ was obtained. However, if the reaction with the same FAL amount was performed in $5 \mathrm{ml}$ of water, higher conversion of $91.4 \%$ was obtained. That is, when we decreased the solvent volume with the same FAL amount, the FAL conversion increased obviously. On the other hand, when we added double amount of FAL in $10 \mathrm{ml}$ of water, the TOF value increased significantly although the conversion decreased.

This observation can be interpreted by the concept of interfacial catalysis. The reactant FAL is slightly soluble in water, while the product FOL is soluble in water, therefore, the hydrogenation of FAL occurs at the interface of water-organic layer. Moreover, the $\mathrm{Pt} / \mathrm{SiC}-\mathrm{C}$ catalyst is more likely soaked well in FAL and FOL. Thus, the reactant FAL can be easily adsorbed on the catalyst surface. When the solvent volume was increased, the interface area between organic reactant and water becomes large so that the FAL concentration on the catalyst surface is lowered. As a result, the reaction rate in more volume solvent is lower than that in smaller one. Additionally, although the solvent and reactant are proportionally increased to double amount, the catalyst amount was kept unchanged so that the concentration of FAL on the catalyst surface was accordingly increased. Finally, the reaction rate was increased instead (Table 4, entry 4).

The recyclability of the $3 \mathrm{wt} \% \mathrm{Pt} / \mathrm{SiC}-\mathrm{C}-200-\mathrm{H}_{2}$ catalyst for the selective hydrogenation of FAL was also investigated, because the stability and reusability of a catalyst is still one of the important concerns. As can be seen in the Fig. 6, the $3 \mathrm{wt} \%$ $\mathrm{Pt} / \mathrm{SiC}-\mathrm{C}-200-\mathrm{H}_{2}$ catalyst can be well recycled during the initial three cycles. However, the activity of the $3 \mathrm{wt} \% \mathrm{Pt} / \mathrm{SiC}-\mathrm{C}-200-\mathrm{H}_{2}$ catalyst declined gradually from the fourth run. Compared to the fresh catalyst, only one third of the FAL conversion is achieved on the used catalyst for the fifth cycle.

To interpret the reason of catalyst deactivation, the filtrate after the fifth run was detected using ICP-OES to check the Pt leaching amount. The results show that the leached Pt amount is below the detection limit of ICP-OES, demonstrating that Pt

Table 4 Selective hydrogenation of FAL with the $3 \mathrm{wt} \% \mathrm{Pt} / \mathrm{SiC}-\mathrm{C}$ $200-\mathrm{H}_{2}$ catalyst with different FAL concentrations ${ }^{a}$

\begin{tabular}{llllll}
\hline & & & & \multicolumn{2}{l}{ Sel. (\%) } \\
\cline { 5 - 6 } Entry & FAL $(\mu \mathrm{l})$ & Water $(\mathrm{ml})$ & Conv. $(\%)$ & FOL & Others \\
\hline 1 & 300 & 15 & 67.7 & 97.8 & 2.2 \\
2 & 300 & 10 & 79.2 & 99.4 & 0.6 \\
3 & 300 & 5 & 91.4 & 98.5 & 1.5 \\
4 & 600 & 10 & 49.6 & 98.4 & 1.6
\end{tabular}

${ }^{a}$ Reaction conditions: $20 \mathrm{mg}$ catalyst, $25^{\circ} \mathrm{C}, 1.0 \mathrm{MPa} \mathrm{H}_{2}, 1200 \mathrm{rpm}, 3 \mathrm{~h}$. Others: THF and THFOL.

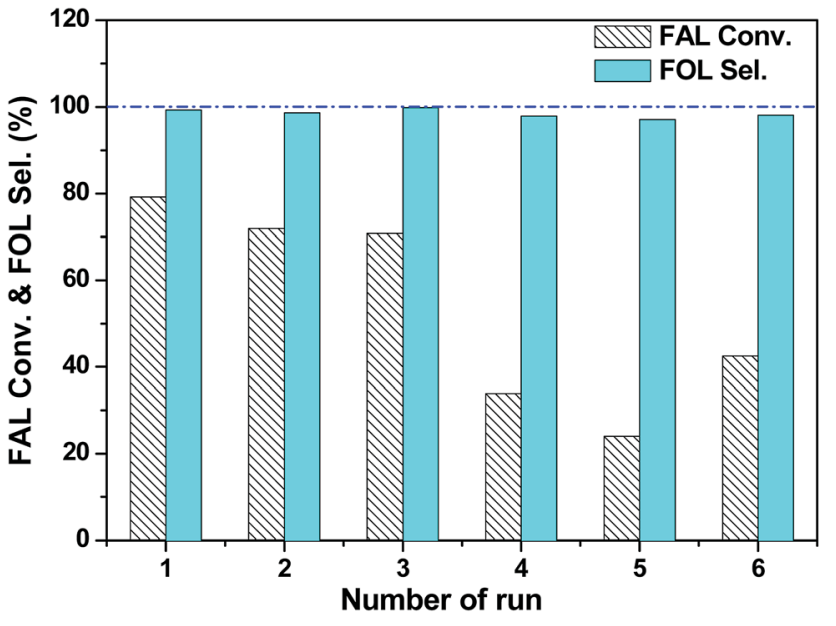

Fig. 6 The recyclability of the $3 \mathrm{wt} \% \mathrm{Pt} / \mathrm{SiC}-\mathrm{C}-200-\mathrm{H}_{2}$ catalyst in the selective hydrogenation of $\mathrm{FAL}$ in neat water at $25{ }^{\circ} \mathrm{C}$. Reaction conditions for the first run: $20 \mathrm{mg}$ catalyst, $0.3 \mathrm{ml} \mathrm{FAL}, 10 \mathrm{ml}$ water, $25^{\circ} \mathrm{C}, 1.0 \mathrm{MPa} \mathrm{H}_{2}, 1200 \mathrm{rpm}, 3 \mathrm{~h}$. After the fifth cycle, the catalyst was filtered and washed with ethanol to remove the strongly adsorbed species on the catalyst surface. For the sixth run, due to weight wastage during washing and characterization by TEM, $10 \mathrm{mg}$ of the recovered catalyst, $5 \mathrm{ml}$ of water and $0.15 \mathrm{ml}$ of $\mathrm{FAL}$ amount was submitted to the reaction.

nanoparticles supported on the SiC-C surface are stable enough during the recycling processes. In addition, we also characterized the used $\mathrm{Pt} / \mathrm{SiC}-\mathrm{C}-200-\mathrm{H}_{2}$ catalyst after five cycles using TEM to check whether Pt nanoparticles are aggregated. As already displayed in Fig. $3 \mathrm{~b}$, the Pt nanoparticles are still uniformly dispersed on the SiC-C surface except that the Pt particle size is slightly increased after 5 reaction cycles in comparison to the fresh one. According to the Pt particle size distribution in Fig. 3b, the Pt particle size of the used $3 \mathrm{wt} \% \mathrm{Pt} /$ SiC-C-200- $\mathrm{H}_{2}$ catalyst after five cycles is centered in $2.2-2.6 \mathrm{~nm}$, with an average Pt particle size of $2.4 \mathrm{~nm}$. Therefore, we can exclude that Pt leaching or Pt particle aggregation is the main cause of the catalyst deactivation.

Thus, we speculate that there are too many FAL or FOL molecules adsorbed on the catalyst surface and cannot desorb from the catalyst surface only through washing with water due to the limited solubility of FAL or FOL in water. Subsequently, we used ethanol to wash the recycled $3 \mathrm{wt} \% \mathrm{Pt} / \mathrm{SiC}-\mathrm{C}-200-\mathrm{H}_{2}$ catalyst and detected the filtrate using GC-FID. As a result, there are indeed FAL and FOL with high concentration in the filtrate, confirming that a lot of FAL and FOL molecules were adsorbed on the catalyst surface. Therefore, we continued to wash the recycled catalyst using ethanol till no FAL or FOL can be detected by GC in the filtrate.

Then, we submitted the washed $3 \mathrm{wt} \% \mathrm{Pt} / \mathrm{SiC}-\mathrm{C}-200-\mathrm{H}_{2}$ catalyst to the sixth run again. It is worthy of note that due to weight wastage during washing and characterization by ICPOES and TEM, only a half weight of the recycled catalyst (10 $\mathrm{mg}$ ) was submitted to the sixth run. Accordingly, the solvent volume (5 $\mathrm{ml}$ of water) and FAL amount $(0.15 \mathrm{ml})$ was reduced to a half. To our surprise, the activity of the used $3 \mathrm{wt} \% \mathrm{Pt} / \mathrm{SiC}-\mathrm{C}-$ $200-\mathrm{H}_{2}$ catalyst was partly recovered. Compared with the results 
obtained for the fifth cycle, twice of FAL conversion was obtained for the sixth run. As for the slight decline in FAL conversion for the sixth run in comparison with the first run, different dosages and volumes of two cycles might be a key reason. Nevertheless, the $3 \mathrm{wt} \% \mathrm{Pt} / \mathrm{SiC}-\mathrm{C}-200-\mathrm{H}_{2}$ catalyst exhibited excellent recyclability if proper solvent was applied to wash the used catalyst. Undoubtedly, the strong interaction between $\mathrm{Pt}$ nanoparticles and $\mathrm{Si}-\mathrm{C}$ composites would benefit the excellent stability of Pt/SiC-C catalyst.

\subsection{Comparison of the $\mathbf{P t} / \mathrm{SiC}-\mathrm{C}$ catalysts with other Pt- based catalysts}

Based on the above discussion, we found that the Pt nanocatalyst supported on the $\mathrm{Si}-\mathrm{C}$ composites exhibited high catalytic performance towards the liquid-phase hydrogenation of FAL to FOL in water at room temperature. In order to understand the $\mathrm{Pt} / \mathrm{SiC}-\mathrm{C}$ catalyst deeply, the catalytic performance of the $\mathrm{Pt} / \mathrm{SiC}-\mathrm{C}$ catalyst towards the liquid-phase hydrogenation of FAL to FOL was compared with Pt catalysts supported on other materials, such as $5 \mathrm{wt} \% \mathrm{Pt} / \mathrm{SBA}-15$ and $\mathrm{Pt} /$ CMK-3 catalysts prepared using the similar methods, in water at $25{ }^{\circ} \mathrm{C}$ under $1 \mathrm{MPa}$ of hydrogen within $5 \mathrm{~h}$. Moreover, the commercial $5 \mathrm{wt} \% \mathrm{Pt} / \mathrm{C}$ and $\mathrm{Pt} / \mathrm{Al}_{2} \mathrm{O}_{3}$ were also applied as reference catalysts.

As shown in Fig. 7A, the Pt catalysts supported on carbon, $\mathrm{Al}_{2} \mathrm{O}_{3}$, ordered mesoporous carbon CMK-3 or periodic mesoporous silica SBA-15 only afford medium FAL conversion (less than $60 \%$ ), although the selectivity to FOL was higher than $95 \%$. As already mentioned above, the $5 \mathrm{wt} \% \mathrm{Pt} / \mathrm{SiC}-\mathrm{C}-\mathrm{H}_{2}$ catalyst shows higher FAL conversion than the other Pt catalysts. About $80 \%$ FAL conversion is obtained on the $5 \mathrm{wt} \% \mathrm{Pt} / \mathrm{SiC}-\mathrm{C}-\mathrm{H}_{2}$ catalyst under the same conditions. Moreover, the selectivity to FOL with the $5 \mathrm{wt} \% \mathrm{Pt} / \mathrm{SiC}-\mathrm{C}-\mathrm{H}_{2}$ catalyst was also higher than those on the other Pt catalysts. Nevertheless, as already discussed above, the $3 \mathrm{wt} \% \mathrm{Pt} / \mathrm{SiC}-\mathrm{C}-200-\mathrm{H}_{2}$ catalyst is more active than its analogue, the $5 \mathrm{wt} \% \mathrm{Pt} / \mathrm{SiC}-\mathrm{C}-\mathrm{H}_{2}$ catalyst. This demonstrates that the $3 \mathrm{wt} \% \mathrm{Pt} / \mathrm{SiC}-\mathrm{C}-200-\mathrm{H}_{2}$ catalyst is the most active and selective one among the Pt catalysts employed in the current work.

Furthermore, we compared the reaction rates (in terms of the converted moles of FAL per gram of Pt per minute) obtained on different Pt catalysts. As displayed in Fig. $7 \mathrm{~B}$, the $\mathrm{Pt} / \mathrm{C}, \mathrm{Pt} / \mathrm{Al}_{2} \mathrm{O}_{3}$, Pt/CMK-3 and Pt/SBA-15 only afford the reaction rate of about 5 $\operatorname{mmol}_{\mathrm{FAL}} \mathrm{g}_{\mathrm{Pt}}{ }^{-1} \mathrm{~min}^{-1}$, while the $5 \mathrm{wt} \% \mathrm{Pt} / \mathrm{SiC}-\mathrm{C}-\mathrm{H}_{2}$ catalyst gives the reaction rate of more than $9.7 \mathrm{mmol}_{\mathrm{FAL}} \mathrm{g}_{\mathrm{Pt}}^{-1} \mathrm{~min}^{-1}$, which is about 2 times of those on the other Pt catalysts. As for the most active $3 \mathrm{wt} \% \mathrm{Pt} / \mathrm{SiC}-\mathrm{C}-200-\mathrm{H}_{2}$ catalyst, the reaction rate can reach $25.1 \mathrm{mmol}_{\mathrm{FAL}} \mathrm{g}_{\mathrm{Pt}}{ }^{-1} \mathrm{~min}^{-1}$ based on the complete conversion within $4 \mathrm{~h}$, about 5 times of those obtained with the other Pt catalysts.

In order to understand the differences between different $\mathrm{Pt}$ catalysts, the related Pt catalysts were characterized using XRD and TEM. All the Pt catalysts show Pt(111) diffraction and the Pt/ SBA-15 catalyst shows the strongest diffraction among all the Pt catalysts (Fig. 8). This might be one of the important reasons for the Pt/SBA-15 catalyst not to behave well for the selective
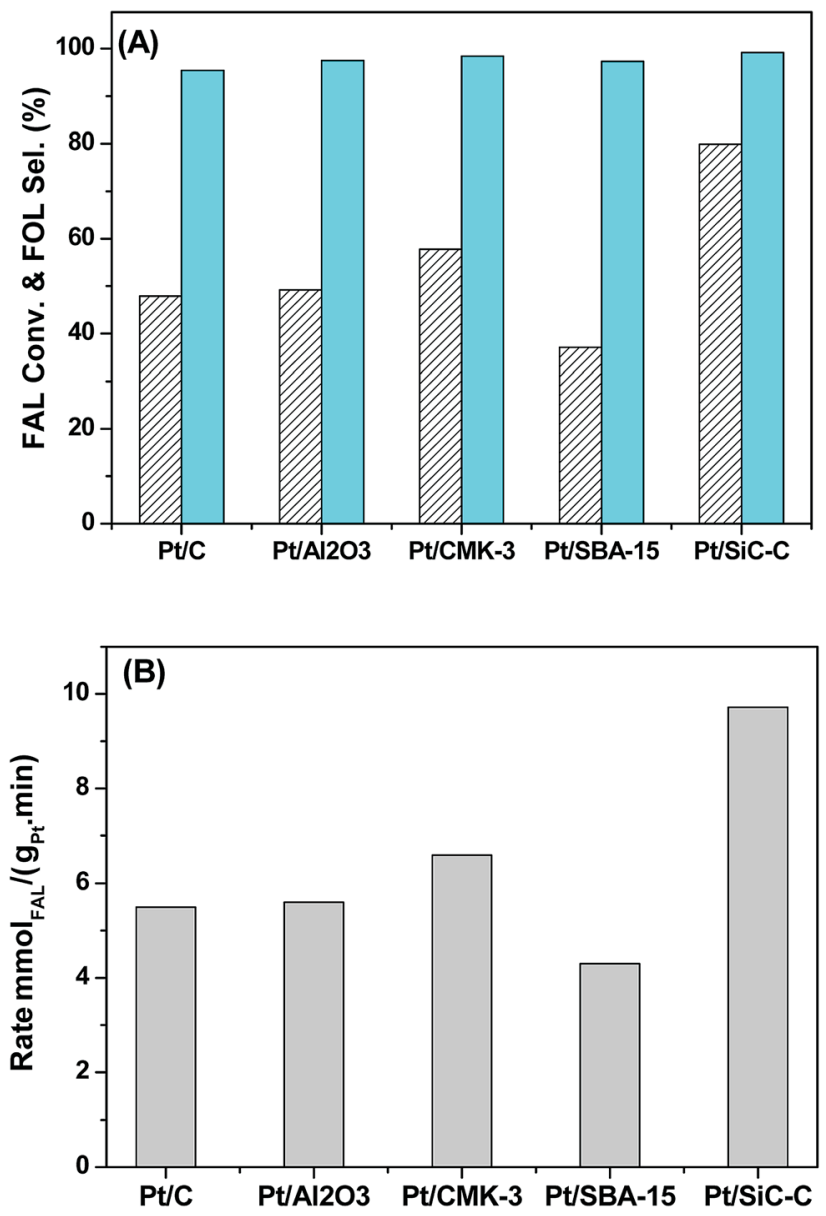

Fig. 7 Reaction results over 5 wt\% Pt catalysts supported on different materials, (A) FAL conversion and FOL selectivity and (B) reaction rate in terms of the moles of the converted FAL per gram of Pt per minute. Reaction conditions: $20 \mathrm{mg}$ catalyst, $0.3 \mathrm{ml} \mathrm{FAL}, 10 \mathrm{ml}$ water, $25^{\circ} \mathrm{C}$, $1.0 \mathrm{MPa} \mathrm{H}_{2}, 1200 \mathrm{rpm}, 5 \mathrm{~h}$.

hydrogenation of FAL. With regards to Pt catalysts supported on activated carbon, CMK-3 or alumina, only rather weak Pt(111) diffraction is observed, suggesting that Pt nanoparticles on these supports are uniformly dispersed. The XRD results are in good agreement with the TEM images (Fig. 3). However, when recalling their catalytic performance in the selective hydrogenation of FAL, the Pt catalysts supported on activated carbon, CMK-3 or alumina exhibit inferior performance although they even have smaller Pt particle size compared with the Pt/SiC-C catalyst. This implies that the Pt particle size is not the only important factor to influence the catalytic performance. We propose that the surface electronic property of Pt catalysts plays a vital role in adsorption and activation of carbonyl group in FAL. The SiC-C composites supported Pt catalyst maybe has an optimal surface electronic property so that the adsorption and activation of carbonyl group in FAL would be preferred, which would be discussed later.

We also compared our results with the related Pt catalysts reported in the literature. As clearly listed in Table 5, $50 \mathrm{mg}$ of $5 \mathrm{wt} \% \mathrm{Pt} / \mathrm{Al}_{2} \mathrm{O}_{3}$ catalyst converted $1 \mathrm{~g}$ of $\mathrm{FAL}$ with $17.5 \%$ conversion in isopropanol after $5 \mathrm{~h}$ at $25{ }^{\circ} \mathrm{C}$ with $2 \mathrm{MPa}$ of 


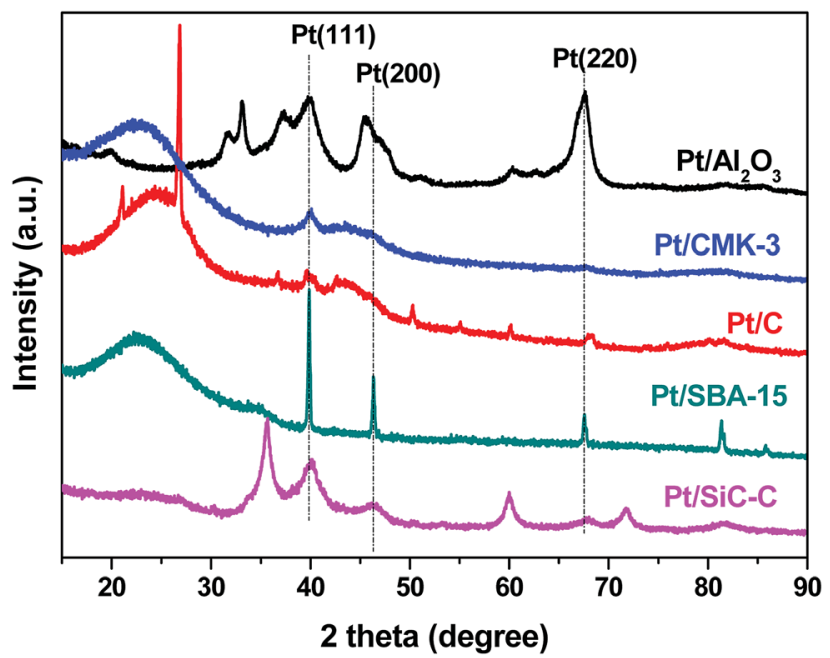

Fig. 8 XRD patterns of $5 \mathrm{wt} \%$ Pt catalysts supported on different materials.

hydrogen, the reaction rate (in terms of the converted moles of FAL per gram of Pt per minute) reaching $2.42 \mathrm{mmol} \mathrm{g}_{\mathrm{Pt}^{-}}$ ${ }^{-1} \min ^{-1} .^{28}$ Another example is that, $20 \mathrm{mg}$ of $2 \mathrm{wt} \% \mathrm{Pt} / \mathrm{Al}_{2} \mathrm{O}_{3}$ catalyst converted $0.02 \mathrm{mmol}$ of FAL with $80.0 \%$ of conversion in methanol after $7 \mathrm{~h}$ at $50{ }^{\circ} \mathrm{C}$. Maybe because the atmospheric hydrogen was adopted, the reaction rate was only $0.095 \mathrm{mmol}$ $\mathrm{g}_{\mathrm{Pt}}{ }^{-1} \mathrm{~min}^{-1}$ as a result. ${ }^{27}$ More recently, $\mathrm{Mu}$ and co-workers carried out the hydrogenation of FAL to FOL with $2.5 \mathrm{wt} \% \mathrm{Pt}$ nanoparticles supported on $\mathrm{g}_{-} \mathrm{C}_{3} \mathrm{~N}_{4}$ graphitic carbon nitride nano-sheets (Pt@TECN). At $100{ }^{\circ} \mathrm{C}$ and in water, the Pt@TECN catalyst afforded a reaction rate of $12.33 \mathrm{~mol} \mathrm{~g}_{\mathrm{Pt}}{ }^{-1} \mathrm{~min}^{-1} \cdot{ }^{29} \mathrm{In}$ this study, we applied $20 \mathrm{mg}$ of $3 \mathrm{wt} \% \mathrm{Pt} / \mathrm{SiC}-\mathrm{C}-200-\mathrm{H}_{2}$ catalyst for the hydrogenation of $0.3 \mathrm{ml} \mathrm{FAL}$ in water at room temperature $\left(25^{\circ} \mathrm{C}\right)$ with $1 \mathrm{MPa}$ of hydrogen. After $3 \mathrm{~h}, 80.2 \%$ conversion was achieved. We calculated the reaction rate using the similar method and the $3 \mathrm{wt} \% \mathrm{Pt} / \mathrm{SiC}-\mathrm{C}-200-\mathrm{H}_{2}$ catalyst give a reaction rate of $26.5 \mathrm{mmol} \mathrm{g}_{\mathrm{Pt}}{ }^{-1} \mathrm{~min}^{-1}$, which is much higher than those in the literature.

\subsection{Further characterization of the $3 \mathrm{wt} \% \mathrm{Pt} / \mathrm{SiC}-\mathrm{C}-200-\mathrm{H}_{2}$ catalyst and further discussion}

Based on the results and discussion above, the $3 \mathrm{wt} \% \mathrm{Pt} / \mathrm{SiC}-\mathrm{C}-$ $200-\mathrm{H}_{2}$ catalyst is very active and selective for the selective hydrogenation of FAL to FOL even the reaction was performed at room temperature. To understand the superiority of the SiCC supported Pt catalyst, the $3 \mathrm{wt} \% \mathrm{Pt} / \mathrm{SiC}-\mathrm{C}-200-\mathrm{H}_{2}$ catalyst was further characterized using XPS technique after in situ pretreatment in flowing hydrogen at $400{ }^{\circ} \mathrm{C}$ for $2 \mathrm{~h}$. Fig. 9A shows the C 1s spectra of the catalyst. Besides the typical C 1s peak $(282.9 \mathrm{eV})$ attributed to $\mathrm{SiC}$, there are abundant $\mathrm{C} 1 \mathrm{~s}$ species assigning to amorphous carbon $(284.9 \mathrm{eV})$ or graphene carbon. ${ }^{33}$ In addition, there are also some carbon species with higher binding energies (285.9 and $298.5 \mathrm{eV}$ ) attributed to organic groups. As for the Si $2 p$ spectra (Fig. 9B), there are dominant Si 2p species which can be assigned to SiC $(100.8 \mathrm{eV})$, in accompany with $\mathrm{Si} 2 \mathrm{p}$ species attributed to $\mathrm{SiO}_{2}(102.8 \mathrm{eV})$.

Fig. 9C displays the Pt $4 \mathrm{f}$ spectra of the $3 \mathrm{wt} \% \mathrm{Pt} / \mathrm{SiC}-\mathrm{C}-200-$ $\mathrm{H}_{2}$ catalyst. It can be deconvoluted to four peaks for two Pt species. The stronger peaks at 72.1 and $75.4 \mathrm{eV}$ for $\mathrm{Pt} 4 \mathrm{f}_{7 / 2}$ and $\mathrm{Pt}$ $4 \mathrm{f}_{5 / 2}$ are higher than those for $\mathrm{Pt}^{0}$, but lower than those for $\mathrm{Pt}^{2+}$, so it can be attributed to $\mathrm{Pt}^{\delta+}$. The other doublet at 74.1 and $77.4 \mathrm{eV}$ could be assigned to $\mathrm{Pt}^{2+} .22,33$ Compared with the conventional supported Pt catalysts, there are obvious shift in binding energy to the higher energy. This suggests that there is very strong interaction between Pt nanoparticles and SiC-C composites, which might be formed during calcination of the catalyst precursor and the reduction process in flowing hydrogen. The strong interaction caused predominant $\mathrm{Pt}^{\delta+}$ species on the catalyst surface, while the $\mathrm{Pt}^{\delta+}$ species are beneficial to the adsorption and activation of FAL through the interaction of $\mathrm{Pt}^{\delta+}$ species with the oxygen atom in carbonyl group of FAL, so that the selectivity to FOL is greatly improved with the $\mathrm{Pt} / \mathrm{SiC}-\mathrm{C}$ catalyst.

With regards to the Pt catalysts supported on other materials, SBA-15, the ordered mesoporous silica, is regarded as one of the inert supports, which would not have interaction with Pt nanoparticles so that the electronic disturbance to Pt surface property can be ignored. As for the Pt/CMK-3 and $\mathrm{Pt} / \mathrm{Al}_{2} \mathrm{O}_{3}$ catalysts, we have characterized using CO-probed diffuse reflectance infrared Fourier-transformation spectroscopy in our previous studies. ${ }^{37}$ As a result, the Pt/CMK-3 catalyst has a high electron density and thus there is an electrostatic repulsion to $\mathrm{CO}$ molecules, while the commercial $\mathrm{Pt} / \mathrm{Al}_{2} \mathrm{O}_{3}$ catalyst gave a CO-linearly adsorbed band at $2083 \mathrm{~cm}^{-1}$ together with a shoulder band at $2050 \mathrm{~cm}^{-1}$, assignable to $\mathrm{Pt}^{\delta+}$ and $\mathrm{Pt}^{0}$ atoms, respectively. Correspondingly, different support materials have different interaction with Pt nanoparticles so that the supported Pt catalysts behave differently in the liquid-phase hydrogenation of FAL in water at room temperature.

The SiC-C composite supported Pt catalysts after optimization of preparation parameters have high and uniform $\mathrm{Pt}$ dispersion, optimal Pt particle size and optimal interaction with

Table 5 Comparison of FAL hydrogenation results obtained with different Pt catalysts from the literature

\begin{tabular}{|c|c|c|c|c|c|c|c|c|}
\hline Catalyst & Amount (mg) & FAL amount & $T\left({ }^{\circ} \mathrm{C}\right)$ & $P_{\mathrm{H}_{2}}$ & $t(\mathrm{~h})$ & Conv. (\%) & $\begin{array}{l}\text { Rate } \\
\left(\mathrm{mmol} \mathrm{g}{ }_{\mathrm{Pt}}^{-1} \mathrm{~min}^{-1}\right)\end{array}$ & Ref. \\
\hline $5 \% \mathrm{Pt} / \mathrm{Al}_{2} \mathrm{O}_{3}$ & 50 & $1 \mathrm{~g}$ in $20 \mathrm{ml}$ isopropanol & 25 & $2.0 \mathrm{MPa}$ & 5 & 17.5 & 2.42 & 28 \\
\hline $2 \% \mathrm{Pt} / \mathrm{Al}_{2} \mathrm{O}_{3}$ & 20 & $0.02 \mathrm{mmol}$ in methanol & 50 & Ambient & 7 & 80.0 & 0.095 & 27 \\
\hline 2.5\% Pt@TECN & 50 & $0.4 \mathrm{ml}$ in $20 \mathrm{ml}$ water & 100 & $1.0 \mathrm{MPa}$ & 5 & 95.9 & 12.3 & 29 \\
\hline $3 \% \mathrm{Pt} / \mathrm{SiC}-\mathrm{C}$ & 20 & $0.3 \mathrm{ml}$ in $10 \mathrm{ml}$ water & 25 & $1.0 \mathrm{MPa}$ & 3 & 80.2 & 26.5 & This study \\
\hline
\end{tabular}



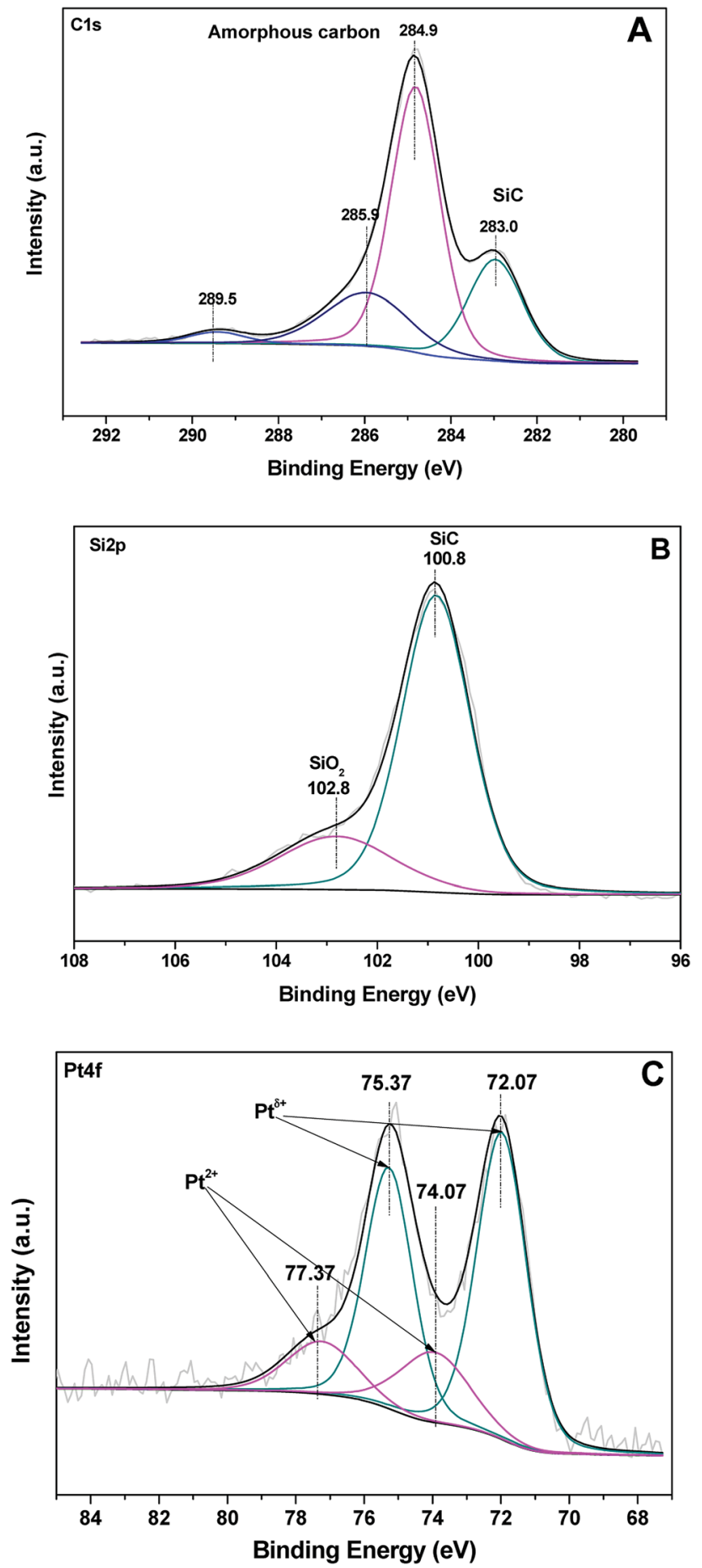

Fig. 9 (A) $\mathrm{C}$ 1s, (B) Si $2 \mathrm{p}$ and (C) Pt 4 f XPS spectra of the $3 \mathrm{wt} \% \mathrm{Pt} / \mathrm{SiC}-$ $\mathrm{C}-200-\mathrm{H}_{2}$ catalyst after in situ pretreatment in flowing hydrogen at $400{ }^{\circ} \mathrm{C}$ for $2 \mathrm{~h}$.

Pt nanoparticles after calcination in static air at $200{ }^{\circ} \mathrm{C}$. These physico-chemical properties of the $\mathrm{Pt} / \mathrm{SiC}-\mathrm{C}$ catalysts determine that the $\mathrm{Pt} / \mathrm{SiC}-\mathrm{C}$ catalyst exhibit superior catalytic performance in the liquid-phase hydrogenation of FAL even at room temperature.

\section{Conclusions}

In summary, the Pt nanocatalyst supported on SiC-C composite shows superior activity and selectivity to other Pt catalysts supported on conventional materials, such as SBA-15, CMK-3, $\mathrm{Al}_{2} \mathrm{O}_{3}$ and carbon, in the liquid-phase selective hydrogenation of FAL in water at room temperature. The SiC-C composite has the advantages of carbon and $\mathrm{SiC}$, so that the $\mathrm{SiC}-\mathrm{C}$ composite has large specific surface area and Pt nanoparticles can be highly and uniformly dispersed on its surface with an average Pt particle size of $1.8 \mathrm{~nm}$. Furthermore, there is special and optimal interaction between $\mathrm{Pt}$ nanoparticles and $\mathrm{SiC}-\mathrm{C}$ composite, which makes the uniform dispersion of Pt nanoparticles and predominant $\mathrm{Pt}^{\delta+}$ species on the catalyst surface. These physico-chemical properties of the $\mathrm{Pt} / \mathrm{SiC}-\mathrm{C}$ catalysts are beneficial to the adsorption and activation of FAL through the interaction of $\mathrm{Pt}^{\delta+}$ species with the oxygen atom in carbonyl group of FAL, so that the activity and selectivity to FOL is greatly improved with the $\mathrm{Pt} / \mathrm{SiC}-\mathrm{C}$ catalysts.

\section{Conflicts of interest}

There are no conflicts to declare.

\section{Acknowledgements}

This work was supported by the National Natural Science Foundation of China (21273076) and Shanghai Leading Academic Discipline Project (B409).

\section{References}

1 A. Corma, S. lborra and A. Velty, Chem. Rev., 2007, 207, 2411.

2 P. Gallezot, Chem. Soc. Rev., 2012, 41, 1538.

3 I. Delidovich, K. Leonhard and R. Palkovits, Energy Environ. Sci., 2014, 7, 2803.

4 R. A. Sheldon, Green Chem., 2014, 16, 950.

5 M. G. Dohade and P. L. Dhepe, Green Chem., 2017, 19, 1144.

6 R. F. Perez and M. A. Fraga, Green Chem., 2014, 16, 3942.

7 R. S. Rao, R. T. K. Baker and M. A. Vannice, Catal. Lett., 1999, 60, 51.

8 B. M. Nagaraja, A. H. Padmasri, B. David Raju and K. S. Rama Rao, J. Mol. Catal. A: Chem., 2007, 265, 90.

9 K. Yan, G. Wu, T. Lafleur and C. Jarvis, Renewable Sustainable Energy Rev., 2014, 38, 663.

10 R. Rao, A. Dandekar, R. T. K. Baker and M. A. Vannice, J. Catal., 1997, 171, 406.

11 S. Srivastava, N. Solanki, P. Mohanty, K. A. Shah, J. K. Parikh and A. K. Dalai, Catal. Lett., 2015, 145, 81.

12 S. Srivastava, P. Mohanty, J. K. Parikh, A. K. Dalai, S. S. Amritphale and A. K. Khare, Chin. J. Catal., 2015, 36, 933.

13 K. Fulajtarova, T. Sotak, M. Hronec, I. Vavra, E. Dobrocka and M. Omastova, Appl. Catal., A, 2015, 502, 78.

14 M. Ghashghaee, S. Shirvani and M. Ghambarian, Appl. Catal., A, 2017, 545, 134. 
15 Á. O'Driscoll, J. J. Leahy and T. Curtin, Catal. Today, 2017, 279, 194.

16 C. P. Jiménez-Gómez, J. A. Cecilia, R. Moreno-Tost and P. Maireles-Torres, Top. Catal., 2017, 60, 1.

17 S. Shirvani, M. Ghashghaee, V. Farzaneh and S. Sadjadi, Biomass Convers. Biorefin., 2018, 8, 79.

18 J. Zhang and J. Chen, ACS Sustainable Chem. Eng., 2017, 5, 5982.

19 J. Chen, F. Lu, J. Zhang, W. Yu, F. Wang, J. Gao and J. Xu, ChemCatChem, 2013, 5, 2822.

20 Q. Yuan, D. Zhang, L. van Haandel, F. Ye, T. Xue, E. J. M. Hensen and Y. Guan, J. Mol. Catal. A: Chem., 2015, 406, 58.

21 Y. Nakagawa, K. Takada, M. Tamura and K. Tomishige, ACS Catal., 2014, 4, 2718.

22 H. Pan, J. Li, J. Lu, W. Xie, P. Wu and X. Li, J. Catal., 2017, 354, 24.

23 Y. Xue, R. Yao, G. Wang, P. Wu and X. Li, Catal. Sci. Technol., 2017, 7, 6112.

24 H. Pan, X. Li, Y. Yu, J. Li, J. Hu, Y. Guan and P. Wu, J. Mol. Catal. A: Chem., 2015, 399, 1.

25 X. Li, W. Zheng, H. Pan, Y. Yu, L. Chen and P. Wu, J. Catal., 2013, 300, 9.
26 P. D. Vaidya and V. V. Mahajani, Ind. Eng. Chem. Res., 2003, 42, 3881.

27 M. J. Taylor, L. J. Durndell, M. A. Isaacs, C. M. A. Parlett, K. Wilson, A. F. Lee and G. Kyriakou, Appl. Catal., B, 2016, 180, 580 .

28 S. Bhogeswararao and D. Srinivas, J. Catal., 2015, 327, 65.

29 X. F. Chen, L. G. Zhang, B. Zhang, X. C. Guo and X. D. Mu, Sci. Rep., 2016, 6, 28558.

30 J. Zhang, K. Dong, W. Luo and H. Guan, ACS Omega, 2018, 3, 6206.

31 V. V. Pushkarev, N. Musselwhite, K. An, S. Alayoglu and G. A. Somorjai, Nano Lett., 2012, 12, 5196.

32 R. Wu, K. Zhou, C. Y. Yue, J. Wei and Y. Pan, Prog. Mater. Sci., 2015, 72, 1.

33 R. Yao, J. Li, P. Wu and X. Li, RSC Adv., 2016, 6, 81211.

34 R. V. Sharma, U. Das, R. Sammynaiken and A. K. Dalai, Appl. Catal., A, 2013, 454, 127.

35 M. G. Dohade and P. L. Dhepe, Green Chem., 2017, 19, 1144. 36 A. B. Merlo, V. Vetere, J. F. Ruggera and M. L. Casella, Catal. Commun., 2009, 10, 1665.

37 B. Li, X. Li, H. Wang and P. Wu, J. Mol. Catal. A: Chem., 2011, 345, 81. 